\title{
Effectiveness of Mobilization with Movement (Mwm) for Improving Glenohumeral Rotational Deficit in Periarthritis Shoulder
}

\section{Rehman Mir A and Thiyagarajan S* \\ Department of Musculoskeletal and sports, Oxford College of Physiotherapy, India}

${ }^{*}$ Corresponding author: Senthilkumar Thiyagarajan, Department of Musculoskeletal and sports, Oxford College of Physiotherapy, India, Email: senphysio1981@gmail.com

\section{Research Article}

Volume 2 Issue 7

Received Date: August 24, 2018

Published Date: September 03, 2018

\section{Abstract}

Background: The present study was intended to compare the effectiveness of MWM along with therapeutic exercises and therapeutic exercises alone in reducing pain and improving the GH rotational deficits and therefore function of patients diagnosed with periarthritis shoulder.

Objective: To find out and compare the effectiveness of MWM with Therapeutic exercise for reducing pain, disability and improving GH rotations in PA shoulder.

Method: Subjects were divided into Experimental Group A (n=15) and Non Experimental Group B (n=15). Group A was given MWM along with Therapeutic exercises and Group B was given Therapeutic exercises alone. The duration of each treatment was 3 weeks, for a session of 25-30 minutes per session. Outcome measures included were SPADI, Yang's three function test and shoulder ROM.

Results: Unpaired t-test the Pre and Post Scores between groups for pain component \& disability component of SPADI are $\mathrm{t}=0.0917$ at $\mathrm{p}<0.0001$, and $\mathrm{t}=0.0301$ at $\mathrm{p}<0.0001$. Pre and post Yang's three function test are 0.1765 and $<0.0001$, Pre and Post scores for active IR \& passive IR are $t=0.0012$ at $p 0.123$ and $t=0.0028$ at $p<0.0001$ respectively. Pre and Post scores for active ER \& passive ER are $t=0.0004$ at $0.003 \& \mathrm{t}=0.003$ at $\mathrm{p}<0.0001$. Thus there is significant difference between the groups, with respect to SPADI, Yang's three function test and shoulder Range of motion.

Conclusion: MWM proved to be more effective, less time consuming and early restoration of GH rotational deficits than therapeutic exercises in PA shoulder; however, subjects improved significantly with both treatment strategies.

Keywords: Periarthritis Shoulder; GH Rotation Deficits; MWM; SPADI; Yang's three function test 


\section{Journal of Natural \& Ayurvedic Medicine}

Abbreviations: Mww: Mobilization with Movement; SPADI: Shoulder Pain And Disability.

\section{Introduction}

Periarthritis shoulder (PA) universally known as 'Frozen shoulder' is a common problem encountered in general practice, orthopedics, physical therapy and Rehabilitation Clinics. Despite the large no. of patients affected by this chronic disorder causing long term disability, our understanding of the condition is limited. The patient frequently has difficulty dressing, grooming, personal care, reaching perineum (bowel hygiene) and performing overhead activities for a period of several months to years [1]. Periarthritis shoulder (PA) is a condition of varying severity characterized by the gradual development of global limitation of active and passive shoulder motion where radiographic findings other than osteopenia are absent [2].The prevalence of periarthritis shoulder is $2-5 \%$ in the general population, however the actual lifetime prevalence and annual incidence of PA shoulder remains uncertain [3]. It is more prevalent in women, in individual 40-65 years old and diabetic population. The estimated prevalence is $11-30 \%$ in diabetic population and $2-10 \%$ in non-diabetic population [4].

The shoulder range of motion frequently affected is external rotation (ER) than abduction (ABD), which in turn is more limited than internal rotation ((ER limitations > ABD limitations > Internal limitations) [5]. The limitation of external rotation and internal rotation is typically associated with capsular restriction and minor "positional fault" to a joint causing restriction in physiological movement [6,7]. Activity limitation \&participation restriction such as gathering daily necessities, recreation \& sports are limited. Thus results in severe emotional distress and economic hardships on the individual and hence early restoration of the $\mathrm{GH}$ rotational deficits are indispensable $[8,9]$.

\section{Material and Methods}

\section{Subjects}

A total of 30 subjects of both gender with shoulder pain of at least 3 months' duration, diagnosed as periarthritis shoulder in the stiffness phase according to physical examination in the outpatient clinic of the oxford medical college and research center and outpatient department of oxford college of physiotherapy were recruited. Periarthritis shoulder was defined as $\geq 50 \%$ loss of passive movement of the shoulder joint relative to the non-affected side, in one or both movement directions (external rotation or internal rotation). The study was approved by the ethical committee of the oxford education institutions (Table 1 ).

\begin{tabular}{|c|c|}
\hline Inclusion Criteria & Exclusion Criteria \\
\hline Both males and females & $\begin{array}{c}\text { Acute Traumatic injuries of } \\
\text { shoulder. }\end{array}$ \\
\hline $\begin{array}{c}\text { Subjects diagnosed with stage } \\
\text { II and III PA shoulder. }\end{array}$ & Rotator cuff tears. \\
\hline Age 40-65 years. & $\begin{array}{c}\text { Subjects with fractured } \\
\text { shoulder complex. }\end{array}$ \\
\hline With or without Diabetes. & $\begin{array}{c}\text { Subjects with recent } \\
\text { history of surgery on } \\
\text { shoulder. }\end{array}$ \\
\hline $\begin{array}{c}\text { Having painful, stiff shoulder } \\
\text { for at least 3 months. }\end{array}$ & \\
\hline $\begin{array}{c}\text { Having restrictions of ROM } \\
\text { more than 50\% in external or } \\
\text { internal rotation. }\end{array}$ & \\
\hline $\begin{array}{c}\text { Yang's three functions related } \\
\text { tests positive in one or more } \\
\text { component. }\end{array}$ & \\
\hline
\end{tabular}

Table 1: Comparison between Inclusion \& Exclusion criteria.

\section{Study design}

A total of 30 subjects were randomized using a Table 1 of random numbers. They were allocated into two groups. Group A $(n=15)$, were treated with Mulligan's technique along with therapeutic exercises and Group B $(n=15)$ receive therapeutic exercises alone. The patients were followed for 3 weeks.

\section{Treatment Procedures}

Group A: Experimental Group

- MWM Inferior glide: Therapist should place the mobilizing belt close to joint line and is secured around the therapist's waist, parallel to floor and perpendicular to humerus.

- Mobilization: Therapist pulls the belt and shifts his weight backwards to distract the joint laterally.

- Therapist stabilizes the distal humerus with both hands and sustains the lateral distracting force with belt. Meanwhile, the patient performs external rotation or internal rotation of the shoulder actively which should be pain-free.

\section{- MWM Posterior glide:}




\section{Journal of Natural \& Ayurvedic Medicine}

a. Subject position: Supine lying with folded towel under the scapula, the elbow is near the side and flexed to $90^{\circ}$. Therapist position and procedure: Stand on the opposite side of the bed facing the subject and reach across the subject's anteromedial aspect of the head of the humerus with reinforced hands. Apply a pain-free graded posterolateral glide of the humeral head on the glenoid. Instruct the subject to use the cane to push the affected arm into the previously restricted range of external rotation. Sustain the movement for 10 seconds and repeat in sets of 5 to 10 . It is important to maintain the elbow near the side of the trunk and ensure that no pain is experienced during the procedure. Adjust the grade and direction of the glide as needed to achieve pain-free function $[10,11]$. Three sets of 10 repetitions were applied, with a rest interval of $30 \mathrm{~s}$ between each set. Patients were treated for 5 days per week for 3 weeks

\section{Group (B)}

Subjects in this group were given structured therapeutic exercises which include: wand exercises, shoulder wheel exercises, shoulder pulley exercises, pendular exercises, and passive external and internal rotation ROM exercises. These exercises were given 5 days in a week for consecutively for 3 weeks and for a duration of 25 to 30 minutes per session [12,13]. All cases were evaluated using a, SPADI, goniometric Shoulder ROM examination, and Yang's three function test at baseline after completion of treatment sessions and the end of 3 weeks of follow-up $[14,15]$. The treatment outcomes used in this study were: SPADI, goniometric Shoulder ROM examination, and Yang's three function test. Statistical analysis was performed with SPSS version 21 Statistical Software. In addition to descriptive statistics for variables with normal distribution we used a unpaired t-test for group comparison, and paired t-test for intra group comparisons.

\section{Results}

A total of 30 patients; 14 (46.66\%) males and 16 (53.33\%) females, age range 40-65 years, were included in the study. The mean age of the study group was 55.4 years (standard deviation (SD) 8.025). The treatment groups were similar in terms of age sex, involved shoulder, dominant shoulder and accompanying medical diseases ( $p>0.05$ ) (Table 2). According to unpaired t test the Pre and Post Scores between groups for pain component of SPADI are 0.0917 and $<0.0001$, Pre and Post Scores for disability component are 0.0301 and $<0.0001$. Pre and post Yang's three function test are 0.1765 and $<0.0001$, Pre and Post scores for active IR are 0.0012 and 0.123 . Pre and Post scores for passive IR are 0.0028 and $<0.0001$. Pre and Post scores for active ER are 0.0004 and 0.003 . Pre and post scores for passive ER are 0.003 and $<0.0001$. Thus there was a significant difference between the groups, with respect to SPADI, Yang's three function test and shoulder Range of motion. Hence research hypothesis was accepted (Tables 3-6).

\begin{tabular}{|c|c|c|c|c|c|c|}
\hline Variable & Group & $\mathbf{N}$ & Mean & SD & T-Value & P-Value \\
\hline \multirow{2}{*}{ Pre-test Pain Score } & Group A & 15 & 52.93 & 10.5 & \multirow{2}{*}{1.746} & \multirow{2}{*}{0.0917} \\
\hline & Group B & 15 & 60 & 11.64 & & \\
\hline \multirow{2}{*}{ Post-test Pain Score } & Group A & 15 & 14.33 & 11.8 & \multirow{2}{*}{5.81} & \multirow{2}{*}{$<0.0001$} \\
\hline & Group B & 15 & 41 & 13.37 & & \\
\hline \multirow{2}{*}{ Difference Pain Score } & Group A & 15 & 38.6 & 12.67 & \multirow{2}{*}{4.56} & \multirow{2}{*}{$<0.0001$} \\
\hline & Group B & 15 & 19 & 10.75 & & \\
\hline
\end{tabular}

Tables 2: Comparison of Group A \& Group B by Unpaired (Level 1).

\begin{tabular}{|c|c|c|c|c|c|c|}
\hline Variable & Group & $\mathbf{N}$ & Mean & SD & t-value & p-value \\
\hline \multirow{2}{*}{ Pre-test Disability Score } & Group A & 15 & 62.98 & 15.9 & \multirow{2}{*}{2.28} & \multirow{2}{*}{0.0301} \\
\hline & Group B & 15 & 74.5 & 11.31 & & \\
\hline \multirow{2}{*}{ Post-test Disability Score } & Group A & 15 & 16.61 & 10.49 & \multirow{2}{*}{8.6} & \multirow{2}{*}{$<0.0001$} \\
\hline & Group B & 15 & 54.97 & 13.67 & & \\
\hline \multirow{2}{*}{ Difference Disability Score } & Group A & 15 & 46.37 & 11.01 & \multirow{2}{*}{5.67} & \multirow{2}{*}{$<0.0001$} \\
\hline & Group B & 15 & 19.53 & 14.17 & & \\
\hline
\end{tabular}

Tables 3: Comparison of Group A \& Group B by Unpaired (Level 2). 


\section{Journal of Natural \& Ayurvedic Medicine}

\begin{tabular}{|c|c|c|c|c|c|c|}
\hline Variable & Group & $\mathbf{N}$ & Mean & SD & t-value & p-value \\
\hline \multirow{2}{*}{ Pre-test Yang's scores } & Group A & 15 & 47.14 & 15.7 & \multirow{2}{*}{1.387} & \multirow{2}{*}{0.1765} \\
\hline & Group B & 15 & 54.29 & 12.31 & & \\
\hline \multirow{2}{*}{ Post-test Yang's scores } & Group A & 15 & 11.9 & 8.4 & \multirow{2}{*}{7.433} & \multirow{2}{*}{$<0.0001$} \\
\hline & Group B & 15 & 40 & 12 & & \\
\hline \multirow{2}{*}{ Difference Yang's scores } & Group A & 15 & 35.24 & 16.52 & \multirow{2}{*}{4.456} & \multirow{2}{*}{0.0002} \\
\hline & Group B & 15 & 14.29 & 7.65 & & \\
\hline
\end{tabular}

Tables 4: Comparison of Group A \& Group B by Unpaired (Level 3).

\begin{tabular}{|c|c|c|c|c|c|c|}
\hline Variable & Group & $\mathbf{N}$ & Mean & SD & t-value & p-value \\
\hline \multirow{2}{*}{ Pre-test Active IR } & Group A & 15 & 35.53 & 10.41 & \multirow{2}{*}{3.613} & \multirow{2}{*}{0.0012} \\
\hline & Group B & 15 & 49.33 & 10.5 & & \\
\hline \multirow{2}{*}{ Post-test Active IR } & Group A & 15 & 60.67 & 6.51 & \multirow{2}{*}{2.676} & \multirow{2}{*}{0.123} \\
\hline & Group B & 15 & 52.33 & 10.15 & & \\
\hline \multirow{2}{*}{ Difference Active IR } & Group A & 15 & 25.14 & 9.83 & \multirow{2}{*}{8.16} & \multirow{2}{*}{$<0.0001$} \\
\hline & Group B & 15 & 3 & 3.68 & & \\
\hline
\end{tabular}

Tables 5: Comparison of Group A \& Group B by Unpaired (Level 4).

\begin{tabular}{|c|c|c|c|c|c|c|}
\hline Variable & Group & $\mathbf{N}$ & Mean & SD & t-value & p-value \\
\hline \multirow{2}{*}{ Pre-test Active ER } & Group A & 15 & 42.13 & 7.95 & \multirow{2}{*}{3.98} & \multirow{2}{*}{0.0004} \\
\hline & Group B & 15 & 53.66 & 7.9 & & \\
\hline \multirow{2}{*}{ Post-test Active ER } & Group A & 15 & 70 & 5.34 & \multirow{2}{*}{4.141} & \multirow{2}{*}{0.003} \\
\hline & Group B & 15 & 69.33 & 8.42 & & \\
\hline \multirow{2}{*}{ Difference Active ER } & Group A & 15 & 27.87 & 7 & \multirow{2}{*}{6.13} & \multirow{2}{*}{$<0.0001$} \\
\hline & Group B & 15 & 15.67 & 3.2 & & \\
\hline
\end{tabular}

Tables 6: Comparison of Group A \& Group B by Unpaired (Level 5).

\section{Interpretation of Results}

The study was conducted on 30 patients diagnosed with PA shoulder to find the efficacy of MWM along with therapeutic exercises over therapeutic exercises alone. According to unpaired $t$ test the Pre and Post Scores between groups for pain component of SPADI are 0.0917 and <0.0001, Pre and Post Scores for disability component are 0.0301 and $<0.0001$. Pre and post Yang's three function test are 0.1765 and $<0.0001$, Pre and Post scores for active IR are 0.0012 and 0.123.Pre and Post scores for passive IR are 0.0028 and $<0.0001$. Pre and Post scores for active ER are 0.0004 and 0.003 . Pre and post scores for passive ER are 0.003 and $<0.0001$. Thus there is a significant between the groups, with respect to SPADI, Yang's three function test and shoulder Range of motion. Hence research hypothesis was accepted.
Rehman Mir A and Thiyagarajan S. Effectiveness of Mobilization with Movement (Mwm) for Improving Glenohumeral Rotational Deficit in Periarthritis Shoulder. J Nat Ayurvedic Med 2018, 2(7): 000149.

\section{Discussion}

The aim of the study was to find out the effectiveness of MWM for reducing pain, disability and improving functional Glenohumeral rotations in PA shoulder and to compare the effectiveness of mobilization with movement and Therapeutic Exercises on reducing pain, disability and improving functional Glenohumeral rotations in PA shoulder. 30 patients were divided into 2 groups experimental group (A) and non-experimental group (B) who underwent treatment 5 days a week consecutively for 3 weeks to predict the outcome measures shoulder pain and disability index (SPADI), Yang's three Function test and Range of motion.

Cochrane Collaboration of Systematic Reviews in 2014 conducted a systematic review to synthesize available evidence regarding the benefits and harms of manual 


\section{Journal of Natural \& Ayurvedic Medicine}

therapy and physical therapy intervention, alone or in combination, for the treatment of patients with adhesive capsulitis. The review could not find out the effect of combinations of manual therapy and exercise, as most evidence was of low quality. The best available data showed that a combination of manual therapy and exercise may not be as effective as glucocorticoid injection in the short-term. High-quality RCTs are needed to establish the benefits and harms of manual therapy and exercise interventions that reflect actual practice, compared with placebo, no intervention and active interventions with evidence of benefit $[16,17]$.

In previous study conducted by Doner, et al. in to compare the efficacy of Mulligan's technique with stretching exercises for relieving pain and improving functional capacity of the shoulder in patients with adhesive capsulitis in the stiffness phase. The study concluded that after completion of treatment sessions and at the end of 3 months of follow-up Mulligan's technique and passive stretching exercises are both effective in reducing pain, and restoring range of motion and function. However, compared with stretching exercises, Mulligan's technique led to better improvements in terms of pain, range of motion, shoulder scores, and patient and physiotherapist satisfaction $[18,19]$.

According to this Study both the groups Group A and Group B showed improvement with respect to SPADI, Yang's three function test and shoulder range of motion, however in comparison between the groups, Group A showed more Significant improvement in above parameters. This reveals that Mobilization with movement seems to be having an additional effect towards reducing pain and disability in patients suffering from PA shoulder. Hence this study also demonstrates the usefulness of Mobilization with Movement in relieving the pain and reducing the disability for the patients suffering from PA shoulder thus improving the function.

\section{Conclusion}

This study is intended to examine the beneficial effects of MWM along with exercises over therapeutic exercises in patients with PA shoulder. MWM proved to be more effective than therapeutic exercises in the early restoration of rotational deficits in PA shoulder; however, subjects improved significantly with both treatment strategies. MWM is less time consuming and more effective than therapeutic exercises. Hence, it can be used more commonly than therapeutic exercises for patients with PA shoulder.

\section{Conflict of Interest}

The study was approved by Board of Ethics committee for research of "The oxford college of physiotherapy, Bangalore. The study does not cause any mental or physical harm to the subjects involved and there are no risks involved in the study. More over the finding of the study will benefit similar subjects, the profession and the society. Hence the review board has no objections on the conduct of the study.

\section{References}

1. Kelley MJ, Shaffer MA, Kuhn JE, Michener LA, Seitz AL, et al. (2013) Shoulder pain and mobility deficits: adhesive capsulitis: Clinical practice guidelines linked to the International Classification of Functioning, Disability, and Health from the Orthopaedic Section of the American Physical Therapy Association. J Orthop Sport Phys Ther 43(5): A1-A31.

2. Page P, Labbe A (2010) Adhesive capsulitis: use the evidence to integrate your interventions. North Am J Sport Phys Ther NAJSPT. N Am J Sports Phys Ther 5(4): 266-273.

3. Griesser MJ, Harris JD, Campbell JE, Jones GL (2011) Adhesive Capsulitis of the Shoulder. J Bone Jt Surg 93(18):1727-33.

4. Lewis J (2015) Frozen shoulder contracture syndrome-Aetiology, diagnosis and management. Man Ther 20(1): 2-9.

5. Dias R, Cutts S, Massoud S (2005) PA shoulder Bmj. BMJ Publishing Group Ltd 331(7530):1453-1456.

6. Vermeulen HM, Obermann WR, Burger BJ, Kok GJ, Rozing PM, et al. (2008) End-range mobilization techniques in adhesive capsulitis of the shoulder joint: a multiple-subject case report. Phys Ther 80(12): 1204-1213.

7. Hsu JE, Anakwenze OA, Warrender WJ, Abboud JA (2015) Current review of adhesive capsulitis. J Shoulder Elbow Surg 20(3): 50-14.
Rehman Mir A and Thiyagarajan S. Effectiveness of Mobilization with Movement (Mwm) for Improving Glenohumeral Rotational Deficit in Periarthritis Shoulder. J Nat Ayurvedic Med 2018, 2(7): 000149.
Copyright $\subseteq$ Rehman Mir A and Thiyagarajan S. 


\section{Journal of Natural \& Ayurvedic Medicine}

8. Neviaser AS, Hannafin JA (2010) Adhesive Capsulitis A Review of Current Treatment. Am J Sports Med 38(11): 2346-2356.

9. Johnson AJ, Godges JJ, Zimmerman GJ, Ounanian LL (2007) The effect of anterior versus posterior glide joint mobilization on external rotation range of motion in patients with shoulder adhesive capsulitis. J Orthop Sport Phys Ther 37(3): 88-99.

10. Vermeulen HM, Rozing PM, Obermann WR, Cessie LS, Vlieland TPMV (2006) Comparison of high-grade and low-grade mobilization techniques in the management of adhesive capsulitis of the shoulder: randomized controlled trial. Phys Ther 86(3): 355-68.

11. Maricar N, Shacklady C, McLoughlin L (2009) Effect of Maitland mobilization and exercises for the treatment of shoulder adhesive capsulitis: a single-case design. Physiother Theory Pract 25(3): 203-217.

12. Cools AM, Johansson FR, Cagnie B, Cambier DC, Witvrouw EE (2012) Stretching the posterior shoulder structures in subjects with internal rotation deficit: comparison of two stretching techniques. Wiley Online Library 4(1): 56-63.

13. Pajareya K, Chadchavalpanichaya N, Painmanakit S, Kaidwan C, Puttaruksa P, et al. (2004) Effectiveness of physical therapy for patients with adhesive capsulitis: a randomized controlled trial. J Med Assoc Thai 87(5): 473-480.
14. Angst F, Goldhahn J, Pap G, Mannion AF, Roach KE, et al. (2007) Cross-cultural adaptation, reliability and validity of the German Shoulder Pain and Disability Index (SPADI). Rheumatology 46(1): 87-92.

15. Yang J, Lin J (2006) Reliability of function-related tests in patients with shoulder pathologies. J Orthop Sport Phys Ther 36(8): 572-576.

16. Jain TK, Sharma NK (2014) The effectiveness of physiotherapeutic interventions in treatment of frozen shoulder/adhesive capsulitis: A systematic review. J Back Musculoskelet Rehabil 27(3): 247-273.

17. Doner G, Guven Z, Atalay A, Celiker R (2013) Evaluation of Mulligan's Technique for Adhesive Capsulitis of the Shoulder. J Rehabil Med 45(1): 8791.

18. Jewell DV, Riddle DL, Thacker LR (2009) Interventions associated with an increased or decreased likelihood of pain reduction and improved function in patients with adhesive capsulitis: a retrospective cohort study. Phys Ther 89(5): 419429.

19. American Physical Therapy Association (2001) Guide to Physical Therapist Practice $2^{\text {nd }}$ (Edn.), American Physical Therapy Association. Phys Ther 81: 9-746.

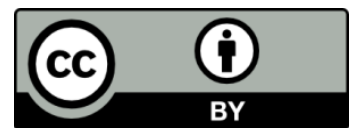

Rehman Mir A and Thiyagarajan S. Effectiveness of Mobilization with Movement (Mwm) for Improving Glenohumeral Rotational Deficit in Copyright@ Rehman Mir A and Thiyagarajan S. Periarthritis Shoulder. J Nat Ayurvedic Med 2018, 2(7): 000149. 